\title{
Field investigation of preferential fissure flow paths with hydrochemical analysis of small-scale sprinkling experiments
}

\author{
D. M. Krzeminska ${ }^{1}$, T. A. Bogaard ${ }^{1}$, T.-H. Debieche ${ }^{2,4}$, F. Cervi ${ }^{2,5}$, V. Marc ${ }^{2}$, and J.-P. Malet ${ }^{3}$ \\ ${ }^{1}$ Water Resources Section, Faculty of Civil Engineering and Geosciences, Delft University of Technology, \\ Delft, Netherlands \\ ${ }^{2}$ Université d'Avignon et des Pays de Vaucluse, EMMAH UMR1114 INRA-UAPV, 33 rue Louis Pasteur, \\ 84000 Avignon, France \\ ${ }^{3}$ Institut de Physique du Globe de Strasbourg, CNRS UMR7516, Université de Strasbourg, Ecole et \\ Observatoire des Sciences de la Terre, 5 rue Descartes, 67084 Strasbourg, France \\ ${ }^{4}$ Water and Environment Team, Geological Engineering Laboratory, Jijel University, P.O. Box 98, 18000 Jijel, \\ Algeria \\ ${ }^{5}$ Dipartimento di Ingegneria Civile, Chimica, Ambientale e dei Materiali (DICAM) Università di Bologna, \\ Viale Risorgimento 2, 40136, Bologna, Italy
}

Correspondence to: D. M. Krzeminska (dkrzeminska@onet.eu)

Received: 6 October 2013 - Published in Earth Surf. Dynam. Discuss.: 30 October 2013

Revised: 27 February 2014 - Accepted: 6 March 2014 - Published: 26 March 2014

\begin{abstract}
The unsaturated zone largely controls groundwater recharge by buffering precipitation while at the same time providing preferential flow paths for infiltration. The importance of preferential flow on landslide hydrology is recognised in the literature; however, its monitoring and quantification remain difficult.

This paper presents a combined hydrological and hydrochemical analysis of small-scale sprinkling experiments. It aims at showing the potential of such experiments for studying the spatial differences in dominant hydrological processes within a landslide. This methodology was tested in the highly heterogeneous black marls of the Super-Sauze landslide. The tests were performed in three areas characterised by different displacement rates, surface morphology and local hydrological conditions. Special attention was paid to testing the potential of small-scale sprinkling experiments for identifying and characterising preferential flow patterns and dominant hydrological processes.
\end{abstract}

\section{Introduction}

In the last two decades, the understanding of hydrological processes in hillslopes has advanced due to improved monitoring techniques (McDonnell, 1990; Kirchner, 2003; Tromp-van Meerveld and McDonnell, 2006) and, consequently, improved understanding of mass movement dynamics (Haneberg 1991; Uchida et al., 2001; Bogaard et al., 2004; Malet et al., 2005; de Montety et al, 2007; Wienhofer et al, 2011). Nevertheless, current knowledge is still incomplete, especially concerning infiltration and percolation processes, subsurface flow paths and residence time of groundwater (Bogaard et al., 2004). The main difficulties stem from strong heterogeneity of hillslope lithology and spatio-temporal variation of hydrological properties as well as dominant hydrological processes. This is particularly true when dealing with highly heterogeneous, unconsolidated, partly weathered silty-clay sediments, such as black marls. Additionally, in slow-moving clayey landslides, (constant) movement of sliding material results in the formation of fissures, due to compression or extension, in relation to the differential movement and deformation rate (Anderson, 2005; Schulson and Duval, 2009; Niethammer et al., 2012, Walter et al., 2012; Stumpf et al., 2012). Here, the term "fissures" 
refers to geo-mechanically induced cracks that are filled or partly filled with reworked material. Accordingly, the term "preferential flow" refers to rapid water flow bypassing the bulk of the matrix (Beven and Germann, 1982), which develops through the areas where water fluxes are favoured by the presence of fissures.

The presence of fissures creates so-called "dual permeability" or "multiple permeability" systems. Dual permeability theory (Gwo et al., 1995; Greco et al., 2002; Šimůnek et al., 2003; Gerke, 2006; Jarvis, 2007) considers the porous medium as two (or more) interacting and overlapping but yet distinct continua. The water flow occurs in both continua but it is mainly ruled by the fracture continuum (macropore or fissure), which generates preferential flow. This way, the presence of fissures may increase the rate of groundwater recharge (preferential vertical infiltration). On the other hand, it may increase the rate of drainage, which limits the building up of pore water pressure (preferential slope parallel drainage). However, when talking about dead-end fissures (disconnected fissure network, limited drainage capacity), they contribute to maintain high pore water pressures in the surrounding soils (McDonnell, 1990; Pierson, 1983; Van Beek and Van Asch, 1999; Uchida et al., 2001).

The quantification of groundwater recharge, especially by means of preferential flow, is an important point to be tackled for an advanced understanding of hydrological systems in hillslopes and landslides (Savage et al., 2003; Coe et al., 2004; Weiler and McDonnell 2007). However, the complexity of the processes and their high spatial variability make it very difficult to measure preferential flow in the field and to build up process models (Van Schaik, 2010). Various experimental techniques are currently used to gain insight into processes controlling preferential flow, e.g. dye tracing (Flury et al., 1994), tension infiltrometers (Angulo-Jaramillo et al., 1996) and continuous sampling of water drainage (e.g. multisampler Wicky lysimeter; Boll et al., 1992). Nevertheless, a consistent measurement method for evaluating preferential flow has not yet been formulated (Allaire et al., 2009).

Environmental tracing (Kabeya et al., 2007) and artificial tracing (Mali et al., 2007) in combination with hydrological survey are the most convenient investigation methods in field conditions. The experiments vary from laboratory tests (e.g. Allaire-Leung et al., 2000; Larsbo and Jarvis, 2006) to field experiments at different scales (e.g. Collins et al, 2002; Weiler and Naef, 2003; Mali et al., 2007; Kienzler and Naef, 2008). However, there are no plot-scale field measurements dedicated to monitoring and quantifying preferential fissure flow, being a special case of macropores with apertures up to tens of centimetres.

The main objective of this research is to test the potential of a small-scale $\left(1 \times 1 \mathrm{~m}^{2}\right)$ sprinkling experiment to identify, study and quantify the dominant hydrological processes within an active, highly heterogeneous landslide. The idea of using small-scale $\left(1 \times 1 \mathrm{~m}^{2}\right)$ sprinkling experiments arose after the successful performance of large-scale (approximately
$100 \mathrm{~m}^{2}$ ) sprinkling tests in summer 2007 at two landslide sites located in France: the Super-Sauze landslide and the Laval landslide (Debieche et al., 2012; Garel et al., 2012). These two experiments gave valuable insight into the preferential infiltration and preferential later drainage processes in those unstable clay-shale hillslopes. However, due to the size and long duration, these kinds of experiments are logistically and financially very demanding, and cannot be undertaken on a regular basis across the study area.

This paper presents the results obtained from three smallscale sprinkling tests performed on morphologically different areas of the persistently active Super-Sauze landslide (French Alps). The hydrological and hydrochemical observations were generalised into flow regimes and collated with current knowledge about the landslide.

\section{Methodology}

\subsection{Experimental design}

The sprinkling experiments were performed with the use of a sprinkling apparatus with one nozzle (1/4HH-10SQ), which was fixed at the top centre at around $2 \mathrm{~m}$ high. The apparatus was calibrated in order to provide a relatively homogeneous distribution of the sprinkling water over the $1 \times 1 \mathrm{~m}^{2}$ experimental plot. Water supply was pumped in with regulated constant pressure (1.1 bars). The sprinkling was carried out in blocks of 15 min sprinkling and 15 min break, with sprinkling intensity of approximately $20-30 \mathrm{~mm} 15 \mathrm{~min}^{-1}$. This intensity is a trade-off between the feasibility of the sprinkling equipment (pump and nozzle) and a realistic sprinkling rate (applied intensity is comparable to the observed intensity of summer and autumn storms reaching $50 \mathrm{~mm} \mathrm{~h}^{-1}$ in 15 minutes; Malet et al., 2003). Moreover, it is optimised to establish a reasonably good spatial distribution and is high enough to ensure infiltration both in the matrix and the fissure compartments. To monitor the actual sprinkling volume, and determine its distribution within the sprinkling plots, rain gauges (five per plot) were installed. In order to protect the experiment from wind disturbances and to minimise evaporation, the experimental areas were covered with a tent. It is important to stress that the setup of the sprinkling experiment was designed to identify different patterns of the hydrological responses rather than being used for, as an example, infiltration capacity measurement.

The $1 \times 1 \mathrm{~m}^{2}$ sprinkling tests were carried out in two periods of 7-8 h sprinkling, composed of 14-17 sprinkling blocks ( $\mathrm{SB}=15 \mathrm{~min}$ rain +15 min break), during two consecutive days. This way, the first day of each sprinkling test started with dry initial conditions, while the second one represented wet initial conditions. The water used for the sprinkling tests was first collected in water tanks and blended with chemical tracers. The artificial tracing was introduced in order to get insight into the subsurface water flow paths and event and pre-event water mixing proportions. Therefore, the 
tracing was realised with two tracers: bromide $\left(\mathrm{Br}^{-}\right)$during the first day of experiment and chloride $\left(\mathrm{Cl}^{-}\right)$during the second day.

Within each sprinkling plot 4-5 piezometers were installed: one in the middle of the plot, two in the direction of the expected (sub-)surface water movement (in the direction of the fissures, if they were visible at the surface), and one upslope with respect to the plot, as a reference (Fig. 1b). The piezometers were made of PVC tubes with $0.50 \mathrm{~m}$ filters, covered with standard filter protection, surrounded by filter sand and closed with granular bentonite. All three experimental setups were built up 2 days before the sprinkling experiment started.

Groundwater responses were monitored manually every $15 \mathrm{~min}$ and with the use of automatic recording water pressure devices (Diver and Keller devices with reported measurement accuracy of $5 \mathrm{~mm}$ ) with a $3 \mathrm{~min}$ time resolution. The water for hydrochemical analyses was sampled every $1 \mathrm{~h}$ from all piezometers during the sprinkling experiment and one time per day for two consecutive days after the experiment. Additionally, the sprinkling plots were equipped with $1 \mathrm{~m}$ long access tubes for theta probes (PR1/6w-02, Delta-T Devices, with reported accuracy of $\pm 0.06 \mathrm{~m}^{3} \mathrm{~m}^{-3}$; Van Bavel and Nichols, 2002) in order to monitor changes in the soil moisture profile at six depths $(0.1,0.2,0.3,0.4,0.6$ and $1.0 \mathrm{~m}$ ). If the installation of theta probes was not possible (e.g. technical problems), the initial surface soil moisture $(0-0.10 \mathrm{~m}$ depth) was measured with a manual field-operated time-domain reflectometry probe (FOM TDR). The reported accuracy of the FOM TDR is $\pm 0.02 \mathrm{~m}^{3} \mathrm{~m}^{-3}$ (IA PAS, 2006).

\subsection{Analysis methodology}

The soil column for water balance and tracer mass balance calculation was bounded laterally by the $1 \times 1 \mathrm{~m}^{2}$ sprinkling surface area and vertically by the maximum depth of the piezometer installed in the centre of each plot. The water balance of the sprinkling experiment for 7 or $8 \mathrm{~h}$ duration is

$P+\mathrm{GW}_{\text {in }}=\mathrm{GW}_{\text {out }}+\mathrm{OF}+E+\Delta S$,

where $P$ is the precipitation (sprinkling), which represents the amount of sprinkling water; $\mathrm{GW}_{\text {in }}$ and $\mathrm{GW}_{\text {out }}$ are the groundwater inflow and outflow; OF is the overland flow; $E$ is the evaporation; and $\Delta S$ is the change in storage over the duration of the sprinkling experiment. The groundwater outflow includes subsurface flow (SSF) and vertical "deep percolation" (Pe). Here we define the "deep percolation" flux as the water flowing down the lowest piezometric observation point in the experimental plot (see Fig. 4).

Moreover, a depletion curve analysis was applied with the analogy of hydrograph recession analysis by using the linear reservoir concept (Hornberger et al., 1991; Mikovari and Leibundgut, 1995; Sivapalan et al., 2002). Additionally, assuming that the groundwater level is a direct function of a change in drained volumes (therefore, a change in storage), it was possible to identify differences in types of storages based on the occurrence of inflexion points in the drawdown curves. The time for the depletion of the storages is indicated by a depletion factor $(K)$ calculated for all segments of the drawdown curve using the empirical method explained by Linsley et al. (1982):

$h_{t+\Delta t}=h_{t} \cdot e^{\frac{-\Delta t}{K}}$,

where $h_{t}$ is the groundwater level at time $t$ and $\Delta t$ is the temporal resolution of groundwater level observations ( $\mathrm{min}$ ). In general, the steeper part of the curve represents fast drainage, assumed to be preferential flow, whereas the gentle slope part represents slower drainage, associated with matrix flow.

Besides a qualitative description of the infiltration process, the concentration of the conservative tracers $\left(\mathrm{Br}^{-}\right.$and $\mathrm{Cl}^{-}$) was used to calculate the proportion of different water sources (event vs. pre-event water) using a two-component end-member mixing (EMMA) model. The EMMA model has been widely used for hydrological studies to separate the different contributions of streamflow (Christophersen and Hooper, 1992; Mulholland and Hill, 1997; Soulsby et al., 2003; James and Roulet, 2006; Cras et al., 2007). The end members are usually defined from the reservoir characteristics; therefore mixing diagrams inform about the variable source areas of runoff. At the same time, they could be used to understand the flow processes which take place during infiltration. The mixing proportions $(\alpha(t)$ and $\beta(t))$ are calculated by solving the following equations:

$\left\{\begin{array}{l}\alpha_{1}(t) \cdot C_{\mathrm{Br}^{-}, \mathrm{EW} 1}+\beta_{1}(t) \cdot C_{\mathrm{Br}^{-}, \mathrm{PE}}=C_{\mathrm{Br}^{-}}(t) \\ \alpha_{2}(t) \cdot C_{\mathrm{Cl}^{-}, \mathrm{EW} 2}+\beta_{2}(t) \cdot C_{\mathrm{Cl}^{-}, \mathrm{PE}}=C_{\mathrm{Cl}^{-}}(t) \\ \alpha_{1,2}(t)+\beta_{1,2}(t)=1,\end{array}\right.$

where $C_{\mathrm{Br} / \mathrm{Cl} \text {,Ew/PE }}$ and $C_{\mathrm{Br} / \mathrm{Cl}}(t)$ are tracer concentrations $\left[\mathrm{mg} \mathrm{L}^{-1}\right]$ measured during the sprinkling experiment at different times (sampled from piezometers). PE and EW indicate the pre-event and event water, and the numbered indexes are related to the first and second day of experiments, respectively.

Besides the added conservative tracers $\mathrm{Br}^{-}$and $\mathrm{Cl}^{-}$, the sulfate concentration in groundwater prior to the experiment was used as an independent variable to define a "pre-event" end member $\left(C_{\mathrm{SO} 4, \mathrm{PE}}\right)$. Sulphate is the major component of the groundwater chemistry and it can be used as a tracer as long as the impact of the difference between groundwater and rainwater concentrations remains far larger than that of the water-rock interaction. Since this was the case, the applied sprinkling sulfate content $\left(C_{\mathrm{SO}, \mathrm{EW}}\right)$ was considered as the second end member and Eq. (3) was formulated accordingly. The two estimated mixing proportions (for artificial and environmental tracers) for both experiments were plotted to analyse and validate the mixing assumption.

Furthermore, the simple mass balance equations were used (for $\mathrm{Br}^{-}$and $\mathrm{Cl}^{-}$) to estimate the most probable water (and 
(a)

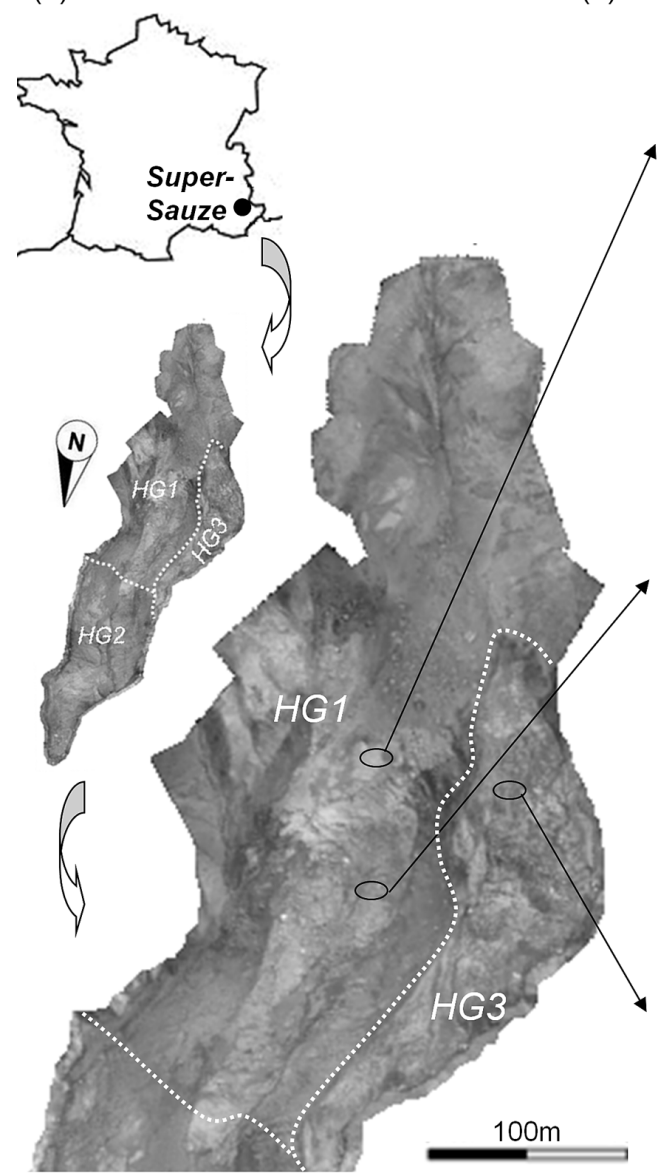

(b)
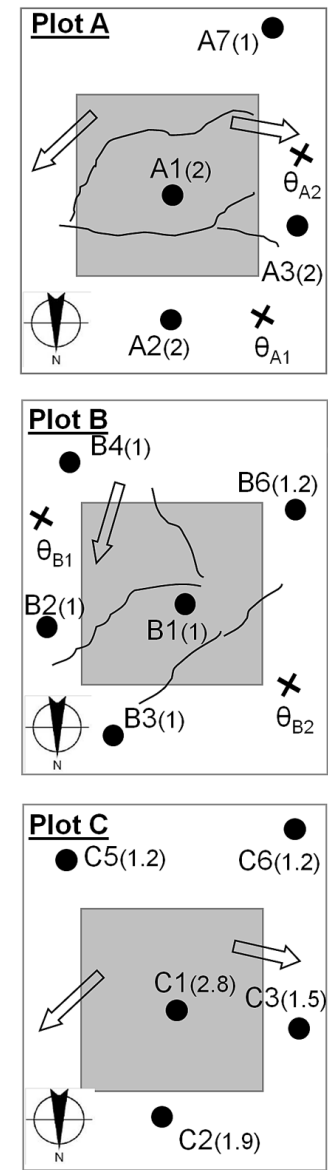

(c)
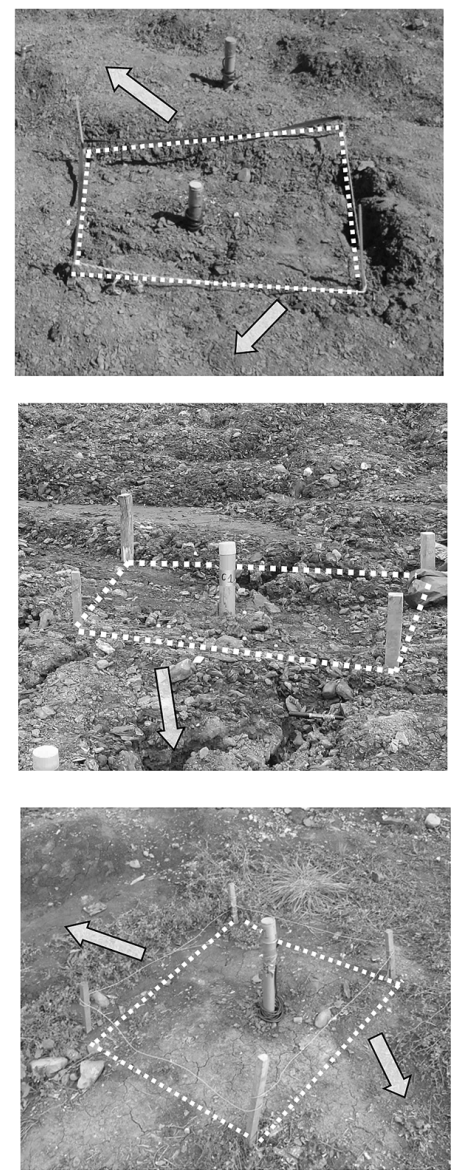

Figure 1. (a) The upper part of the Super-Sauze landslide with indicated location of three sprinkling tests (plot A, B and C); the white dashed lines indicate the hydro-geomorphological units (after Malet et al. 2005). (b) Schematic representation of the experimental setup of each area (not scaled): grey squares represent $1 \times 1 \mathrm{~m}^{2}$ sprinkling plots, dots represent the location of the piezometers, numbers in brackets indicate the depth of the piezometers in metres, crosses indicate the location of the theta probes, undulating lines indicate fissure distribution within the sprinkling plots, and arrows show the local slope direction in the area. (c) Photographs of the soil surface of each sprinkling area with arrows showing the local slope direction in the area.

tracer) flow paths and to restrain mixing processes:

$$
\begin{aligned}
& V\left(t_{\text {end }}\right)=V_{\mathrm{PE}}+V_{\mathrm{INF}}-V_{\mathrm{SSF}} \\
& C_{\mathrm{Br}^{-} / \mathrm{Cl}^{-}}\left(t_{\text {end }}\right) \\
& \cdot V\left(t_{\mathrm{end}}\right)=C_{\mathrm{Br}^{-} / C l^{-}, \mathrm{PE}} \cdot V_{\mathrm{PE}}+C_{\mathrm{Br}^{-} / \mathrm{Cl}^{-}, \mathrm{EW}} \\
& \cdot V_{\mathrm{INF}}-C_{\mathrm{Br}^{-} / C l^{-}}(t) \cdot V_{\mathrm{SSF}},
\end{aligned}
$$

where $V\left(t_{\text {end }}\right), V_{\mathrm{PE}}, V_{\mathrm{INF}}$ and $V_{\mathrm{SSF}}$ are the estimated total water volume in the soil column at the end of sprinkling tests, the estimated volume of pre-event water, the estimated volume of infiltrated water (fraction of EW) and the estimated volume of subsurface flow (including exfiltration), respectively. The volume of pre-event $\left(V_{\mathrm{PE}}\right)$ was calculated based on the initial groundwater level and initial soil moisture content as follows:

$V_{\mathrm{PE}}=A \cdot\left(h_{t_{0}} \cdot n+\left(z-h_{t_{0}}\right) \cdot \theta_{\mathrm{ini}}\right)$,

where $A$ is the plot area $\left(\mathrm{m}^{2}\right), h_{t 0}$ is the groundwater level (m) observed before the experiment, $n$ is the average porosity (-), $z$ is the depth of the analysed soil column (m) and $\theta_{\text {ini }}$ is the initial soil moisture (-).

\subsection{Characteristics of experimental plots}

The experimental design was tested at the highly active Super-Sauze landslide (Fig. 1a), which covers $0.17 \mathrm{~km}^{2}$ with an average slope of $25^{\circ}$ and has displacement velocities varying from 0.01 to $0.40 \mathrm{~m} \mathrm{day}^{-1}$, depending on the season (Malet et al., 2002). The small-scale sprinkling plots $\mathrm{A}$ and $\mathrm{B}$ are located in the upper part of the landslide, which is the most active in terms of displacement rates, abrupt changes in groundwater levels throughout the season, and changes in fissure density and openings (Fig. 1b). Plot $\mathrm{C}$ is located in a relatively stable part of the landslide, but still at the direct contact with the most active area, and is representative of small displacement rates, small changes in groundwater 
levels throughout the season and no changes in fissure characteristics (Fig. 1b). As such, the three experimental plots shall present different hydrological responses (Malet, 2003; de Montety et al., 2007). All sprinkling experiments were carried out in relatively flat areas with slopes of $5-7^{\circ}$. The porosity values for the experimental plots were assumed to be $0.35,0.38$ and 0.30 on average for plot A, B and C, respectively, based on gravimetric measurements (Malet, 2003). The geomorphology of each plot is detailed below:

- Plot A is located in the active area near the crown consisting of relatively fresh but heavily broken marl blocks and deposits (marly fragments of approximately $2 \mathrm{~cm}$ ). There are wide (aperture of $0.07-0.15 \mathrm{~m}$ ), undulating fissures observed on the surface (see Fig. $1 \mathrm{~b}$ for the sketch), partly or totally filled with reworked marl fragments. The open depth of these fissures varies from 0.09 to $0.12 \mathrm{~m}$.

- Plot B is also located in the very active area, at a secondary mudslide deposition area, that consists of gravel crust, which is characterised by coarse fragments (larger than $2 \mathrm{~mm}$ ) overlaying a finer matrix. There are wide open (apertures around $0.10 \mathrm{~m}$ ) fissures present within the plot area with an open depth reaching $0.50 \mathrm{~m}$ (see Fig. 1b for the sketch).

- Plot C is situated in the compacted, relatively stable, western part of the landslide and consists of fine-grained material with different rock fragments. No fissures are observed at the surface.

The average depth to the bedrock is around $10 \mathrm{~m}$ in plot $\mathrm{A}$, $3 \mathrm{~m}$ in plot B and $5 \mathrm{~m}$ in plot C (Travelletti and Malet, 2012). The depth of the piezometers is different at each area. Within plot A all piezometers were installed at approximately $2 \mathrm{~m}$ depth. Within plot B the piezometers depths are around $1 \mathrm{~m}$ due to the shallow groundwater level (see also Fig. 1b-c.). Within plot $\mathrm{C}$ the depths of the piezometers were conditioned by the presence of rock fragments in the soil and vary from 1.2 to $3.0 \mathrm{~m}$.

\section{Results of sprinkling experiments - hydrological and hydrochemical responses}

Within each sprinkling plot different hydrological behaviours were observed. Fig. 2a-c summarise the observed groundwater variation and tracer concentration patterns. Figure 3 shows the drawdown curves after the second day of sprinkling. For plot $\mathrm{A}$ and $\mathrm{B}$ the drawdown of the centrally located piezometers was analysed (A1 and B1), while for plot $\mathrm{C}$ the analysis was carried out for piezometer $\mathrm{C} 2$ since the groundwater level observed in piezometer $\mathrm{C} 1$ was strongly influenced by water sampling.

\subsection{Plot A}

Plot A was a dry area with no groundwater observed within the first $2 \mathrm{~m}$ depth (depth A1) before the experiment started. The mean initial volumetric water content of the top soil layer (up to $0.30 \mathrm{~m}$ depth) was 0.12 with a standard deviation of 0.03 . In response to the applied sprinkling, neither overland flow nor subsurface runoff was observed. The groundwater fluctuation in A1 showed a very fast vertical movement of water (approximately $\pm 0.25-0.30 \mathrm{~m}$ in $15 \mathrm{~min}$ ). Moreover, the drawdown after each day of sprinkling lasted only $4 \mathrm{~h}$ (Fig. 2a).

In A3, located in the direction of the surface fissures, the groundwater level started to react during the first day, after the fourth sprinkling block (SB-04). In A2, located downslope of the sprinkling plot, but not in the direction of the surface fissures, the groundwater reaction started only during the second day after the fifth sprinkling block (SB-05). There was no response observed in A7.

The soil moisture variation observed in the soil profile in $\theta_{A 2}$ (approximately $1 \mathrm{~m}$ distance from the sprinkling area) was negligible. In $\theta_{A 1}$ no changes were observed in the first $0.60 \mathrm{~m}$ of soil profile. At $1 \mathrm{~m}$ depth soil moisture increased until saturation over the 2 days of the sprinkling experiment.

The tracer concentration in the piezometers gradually increased with the cumulated amount of applied sprinkled water. Similar to the hydrological responses, the most intense changes were observed in A1, reaching $84 \%$ (first day) and $93 \%$ (second day) of applied tracer concentration at the end of each 7-8 h sprinkling. Moreover, the tracer concentration decreased during the recession phase. At the start of the second day, $\mathrm{Br}^{-}$concentration had nearly dropped back to the initial value. The same trend was observed for $\mathrm{Cl}^{-}$during the second day. The tracer concentration in A2 and A3 followed the trend observed in A1, with the maximum measured tracer concentration reaching 26-38\% (first day) and $55-71 \%$ (second day) of applied concentration for A3 and $\mathrm{A} 2$, respectively. It is important to note that in plot $\mathrm{A}$, on the second day of experiment, $\mathrm{Br}^{-}$was applied during the first four sprinkling blocks (SB-01 to SB-04) at very high concentration $\left(461 \mathrm{mg} \mathrm{L}^{-1}\right)$. This incident determined the behaviour of $\mathrm{Br}^{-}$concentration at the beginning of the second day of sprinkling: the maximum concentration of $\mathrm{Br}^{-}$was observed after SB-06 in A1, after SB-08 in A2 and after SB-12 in A3.

\subsection{Plot B}

Plot B was located in an area with shallow groundwater level $(0.35-0.55 \mathrm{~m}$ below the surface). The average initial volumetric water content in the first $0.30 \mathrm{~m}$ of soil was 0.25 , with a standard deviation of 0.07 . During the sprinkling experiment, an increase of groundwater level was observed only in B1 and B3 and it fluctuated $\pm 0.07 \mathrm{~m}$ on average in response to a single sprinkling block. No groundwater level changes were registered in $\mathrm{B} 2$ and $\mathrm{B} 6$, and no changes in 

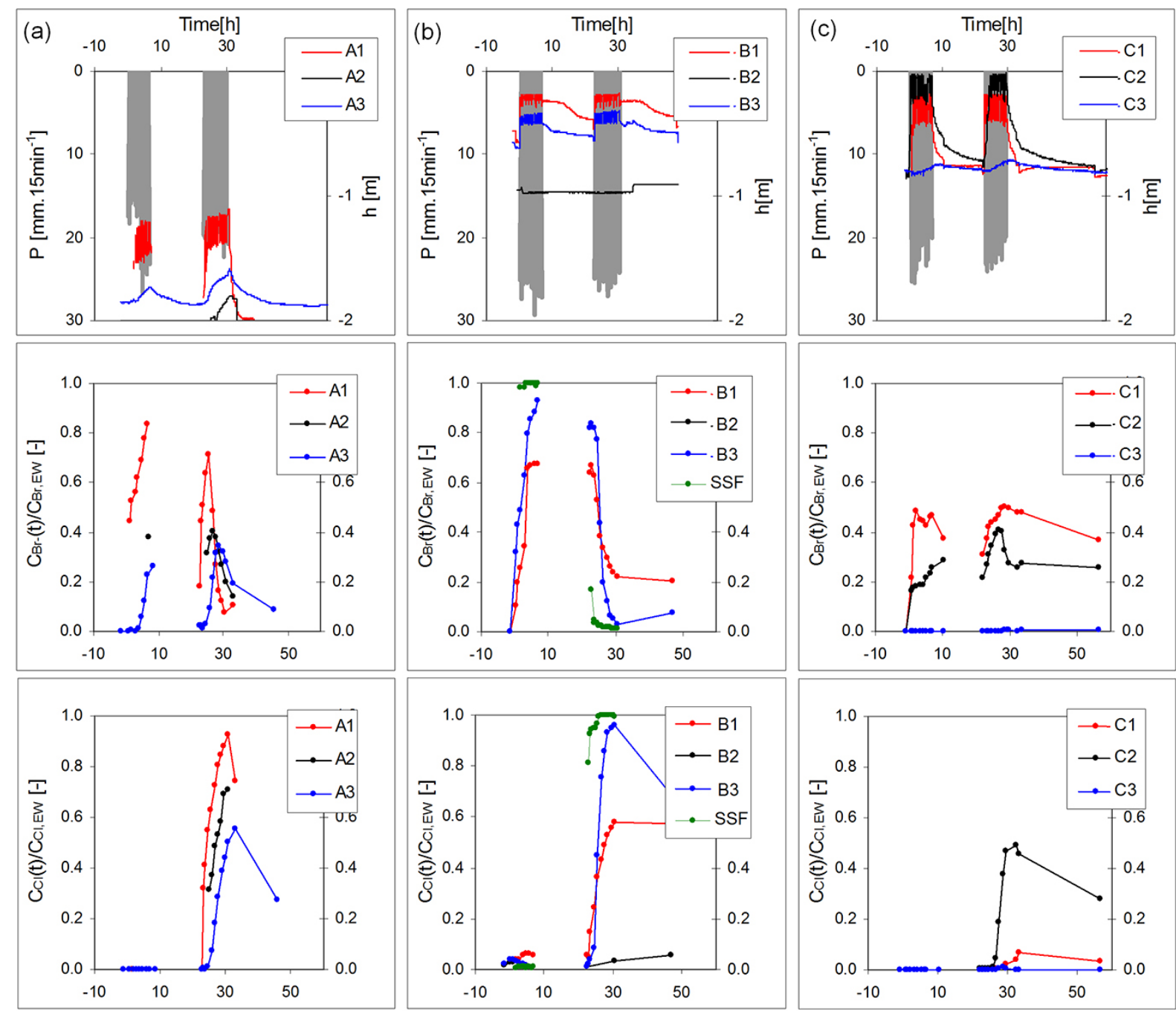

Figure 2. Monitoring results of three sprinkling experiments: (a) plot A, (b) plot B and (c) plot C. Upper panels show the intensity of the sprinkling (primary $y$ axis) and groundwater responses in piezometers (secondary $y$ axis). Middle and bottom panels show the ratio between tracer concentration measured in the piezometers or subsurface runoff (SSF) and the applied tracer concentration.

soil moisture content in $\theta_{\mathrm{B} 1}$ or $\theta_{\mathrm{B} 2}$ (located within a distance of approximately $1 \mathrm{~m}$ from the $1 \times 1 \mathrm{~m}^{2}$ sprinkling plot) were observed.

The exfiltrating subsurface runoff was measured around $1-1.5 \mathrm{~m}$ downslope of the experimental plot. The volume of subsurface runoff per sprinkling block increased with time. During the first day, it started at $15.9 \times 10^{-3} \mathrm{~m}^{3}$ for SB-05 and reached $18.3 \times 10^{-3} \mathrm{~m}^{3}$ for SB-14. During the second day, it ranged from $11.4 \times 10^{-3} \mathrm{~m}^{3}$ (for SB-01) to $19.5 \times 10^{-3} \mathrm{~m}^{3}$ (for SB-14).

In $\mathrm{B} 1$ and $\mathrm{B} 3$ the relative $\mathrm{Br}^{-}$concentration rose quickly and reached a maximum of 67 and $93 \%$, respectively, at the end of the first day. Moreover, it remained at a high level in between 2 days of sprinkling (Fig.2b). A similar tracer concentration behaviour was observed during the second day of the experiment, when chloride was applied. The observed
$\mathrm{Br}^{-}$concentration gradually decreased, while the $\mathrm{Cl}^{-}$concentration increased, reaching $58 \%$ (B1) and $99 \%$ (B3) of applied concentration. The $\mathrm{Cl}^{-}$concentration remained high (58\% of the applied concentration in B1 and $68 \%$ in B3) even $20 \mathrm{~h}$ after the end of the experiment. It is worth noting that the concentrations of $\mathrm{Br}^{-}$and $\mathrm{Cl}^{-}$were most of the time higher in $\mathrm{B} 3$ than in $\mathrm{B} 1$ and that the tracer concentration in the subsurface runoff equalled (first day) or almost equalled (second day: 81-99\%) that of the sprinkling water.

\subsection{Plot C}

The initial groundwater level at plot $\mathrm{C}$ was around 0.75 $1.00 \mathrm{~m}$ below the surface and the initial volumetric water content varied between 0.20 and 0.25 ( 0.23 on average) in the first $0.10 \mathrm{~m}$ of soil. In contrast to the dynamics observed 


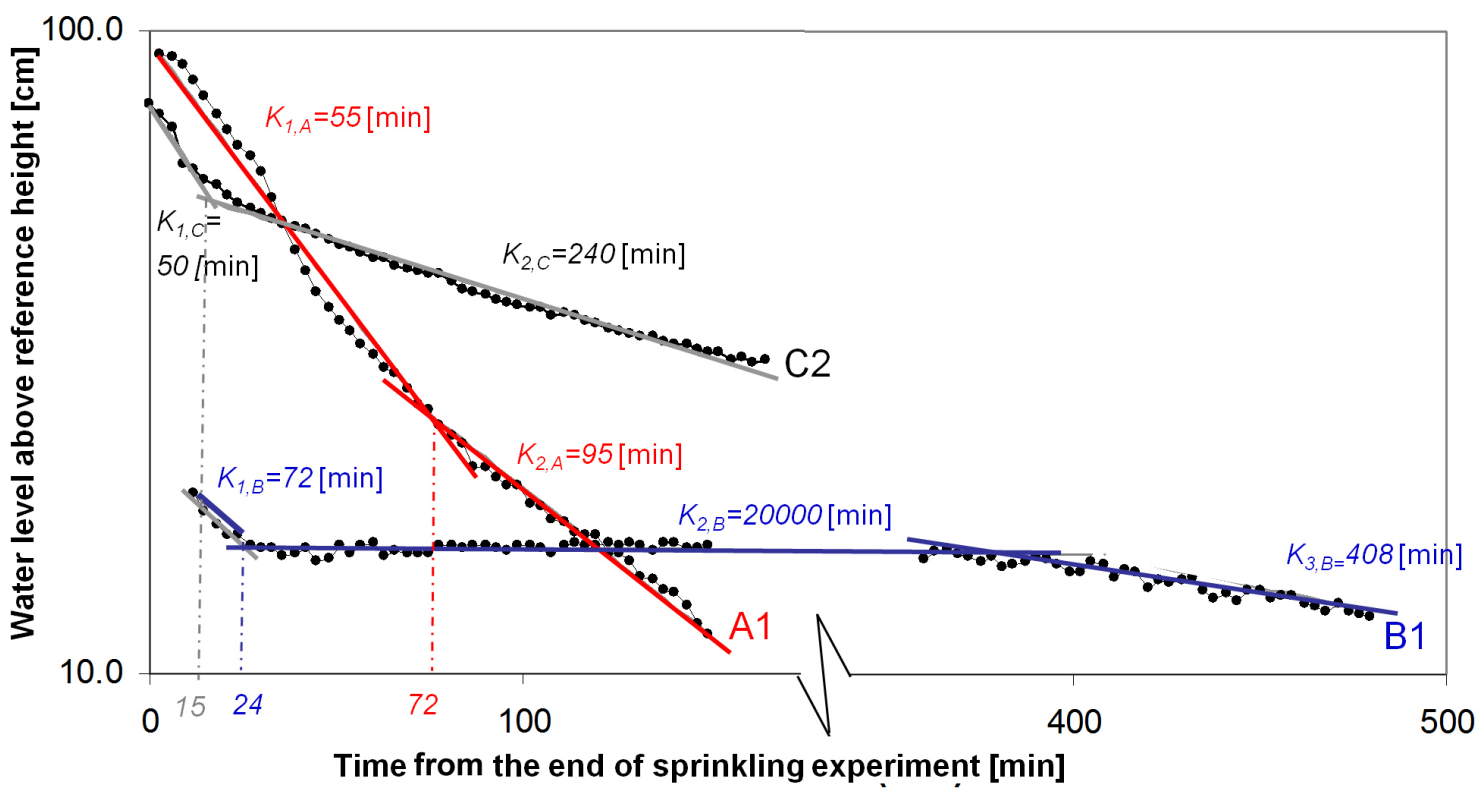

Figure 3. Drawdown curves observed in piezometers A1, B1 and C2 after the end of sprinkling experiments and corresponding depletion factors $K$ [min].

in plot A, $75 \%$ of the sprinkling water left the soil column as overland flow. Moreover, ponding was observed within the $1 \times 1 \mathrm{~m}^{2}$ plot during the entire experiment.

The groundwater level observed in $\mathrm{C} 1$ and $\mathrm{C} 2$ responded similarly: an increase of groundwater level up to $0.20 \mathrm{~m}$ (for $\mathrm{C} 1$ ) and $0.05 \mathrm{~m}$ (for $\mathrm{C} 2$ ) below the surface and fluctuations of about $0.20 \mathrm{~m}$ after each $15 \mathrm{~min}$ of sprinkling. The drawdown observed in $\mathrm{C} 1$ stopped after $4 \mathrm{~h}$, whereas in $\mathrm{B} 2$ it lasted around $12 \mathrm{~h}$ after the sprinkling experiment. $\mathrm{C} 3$ showed a 0.03-0.07 m groundwater level fluctuation, and no response took place in C5 and C6. The groundwater level in the soil column went back to its initial stage within 12 hours after the sprinkling ceased.

In $\mathrm{C} 1$ the relative concentration of $\mathrm{Br}^{-}$reached approximately $43-49 \%$ of the applied tracer concentration and was relatively constant during the first day of sprinkling. At the start of the second day $\mathrm{Br}^{-}$relative concentration was $31 \%$, and it rose again up to $50 \%$ as soon as new sprinkling water (without $\mathrm{Br}^{-}$) was applied (Fig. 2c). Similar trends were observed for $\mathrm{C} 2$, with the maximal tracer concentration reaching 28 and $40 \%$ of applied concentration for the first and second day, respectively. No tracer was found in C3.

During the second day of the sprinkling experiment, the $\mathrm{Cl}^{-}$concentration showed a very limited increase in $\mathrm{C} 1$ but a gradual increase up to around $50 \%$ of the applied concentration in $\mathrm{C} 2$. The $\mathrm{Cl}^{-}$concentration decreased after the second day. However, in $\mathrm{C} 2$ it remained relatively high even $20 \mathrm{~h}$ after the experiment $\left(300 \mathrm{mg} \mathrm{L}^{-1}\right)$. Again, no tracer was found in $\mathrm{C} 3$.

\section{Discussion of experimental results and model conceptualisation}

\subsection{Water balance and tracer mass balance analysis}

The water budget was calculated for each day of the sprinkling experiment from the beginning of the first sprinkling block (SB-01) until the end of the drawdown observed in the centrally located piezometer. As a first approximation, the water balance components were estimated based on the assumption that the whole experimental area $\left(1 \times 1 \mathrm{~m}^{2}\right)$ is hydrologically active, meaning all water stored in the soil column is mobile and full mixing of pre-event water and event water occurs. The groundwater flow variations were assumed to be only due to infiltrating sprinkling water over the experimental plot (Fig. 4). This means that we assume no change in overall groundwater flow and no change in deep percolation (plot B and C) due to the sprinkling activity. In the case of plot A, where no groundwater level was observed before and shortly after the experiment, the direction of the estimated subsurface flow could not be determined. Therefore, the subsurface flow comprised both vertical deep percolation $(\mathrm{Pe})$ and lateral flows $(\mathrm{SSF})$. The volume of pre-event $\left(V_{\mathrm{PE}}\right)$ water was estimated based on Eq. (7), and the volume of infiltrated water $\left(V_{\mathrm{INF}}\right)$ was calculated as $V_{\mathrm{EW}}-V_{\mathrm{OF}}$. The volume of subsurface fluxes $\left(V_{\mathrm{SSF}}\right)$, which comprises all subsurface fluxes, was estimated using the measured groundwater level responses to the sprinkling blocks. The change in storage $\Delta S$ was calculated as $V_{\mathrm{INF}}-V_{\mathrm{SSF}}$. Evaporation $(E)$ was assumed to be negligible, as the sprinkling plots were covered with a tent. Table 1 shows the measured $\left({ }^{\mathrm{m}}\right)$ and estimated $\left({ }^{\mathrm{e}}\right)$ water balance components. 
Table 1. Measured $\left({ }^{\mathrm{m}}\right)$ and estimated $\left({ }^{\mathrm{e}}\right)$ components of water balance for each plot, with the assumption that whole experience area is hydrologically active.

\begin{tabular}{|c|c|c|c|c|c|c|}
\hline \multirow[b]{2}{*}{ Day of experiment (duration) } & \multicolumn{2}{|c|}{ Plot A } & \multicolumn{2}{|c|}{ Plot B } & \multicolumn{2}{|c|}{ Plot C } \\
\hline & 1 st $(7 \mathrm{~h})$ & 2nd (8h) & $1 \mathrm{st}(7 \mathrm{~h})$ & 2nd (8h) & $1 \mathrm{st}(7 \mathrm{~h})$ & 2nd (7h) \\
\hline Assumed average porosity, $n[-]$ & 0.35 & 0.35 & 0.38 & 0.38 & 0.30 & 0.30 \\
\hline${ }^{(m)}$ Initial average volumetric soil moisture, $\theta_{\text {ini }}[-]$ & 0.12 & 0.12 & 0.25 & 0.27 & 0.23 & 0.25 \\
\hline${ }^{(\mathrm{e})}$ Water in soil column, $V_{\mathrm{PE}}\left[\mathrm{m}^{3}\right]$ & 0.23 & 0.24 & 0.32 & 0.34 & 0.78 & 0.79 \\
\hline${ }^{(\mathrm{m})}$ Sprinkling volume, $P\left[\mathrm{~m}^{3}\right]$ & 0.27 & 0.33 & 0.36 & 0.42 & 0.29 & 0.30 \\
\hline (m) Overland flow, OF, $\left[\mathrm{m}^{3}\right]$ & \multicolumn{2}{|c|}{ Not observed } & \multicolumn{2}{|c|}{ Not observed } & 0.22 & 0.23 \\
\hline${ }^{(\mathrm{e})}$ Infiltrated water, $V_{\mathrm{INF}}\left[\mathrm{m}^{3}\right]$ & 0.27 & 0.33 & 0.36 & 0.42 & 0.09 & 0.08 \\
\hline (e) Subsurface flow, (SSF) $\left[\mathrm{m}^{3}\right]$ & $-^{*}$ & 0.23 & 0.34 & 0.41 & 0.09 & 0.008 \\
\hline${ }^{(\mathrm{m})}$ exfiltration $\left[\mathrm{m}^{3}\right]$ & \multicolumn{2}{|c|}{ Not observed } & $>0.17^{* *}$ & 0.30 & \multicolumn{2}{|c|}{ Not observed } \\
\hline${ }^{(\mathrm{e})}$ Water in soil column, $V\left(t_{\text {end }}\right)\left[\mathrm{m}^{3}\right]$ & $-^{*}$ & 0.34 & 0.35 & 0.35 & 0.79 & 0.79 \\
\hline (e) Change in storage, $\Delta S\left[\mathrm{~m}^{3}\right]$ & $-^{*}$ & 0.10 & 0.02 & 0.01 & 0.01 & 0.01 \\
\hline (e) Final average volumetric soil moisture, $\theta\left(t_{\text {end }}\right)[-]$ & $--^{*}$ & 0.17 & 0.27 & 0.28 & 0.25 & 0.26 \\
\hline
\end{tabular}

${ }^{*}$ Estimation not possible because of missing groundwater level observation. ${ }^{* *}$ Exfiltration started after $2 \mathrm{~h}$ of sprinkling but was measured only from the third hour of the sprinkling experiment.

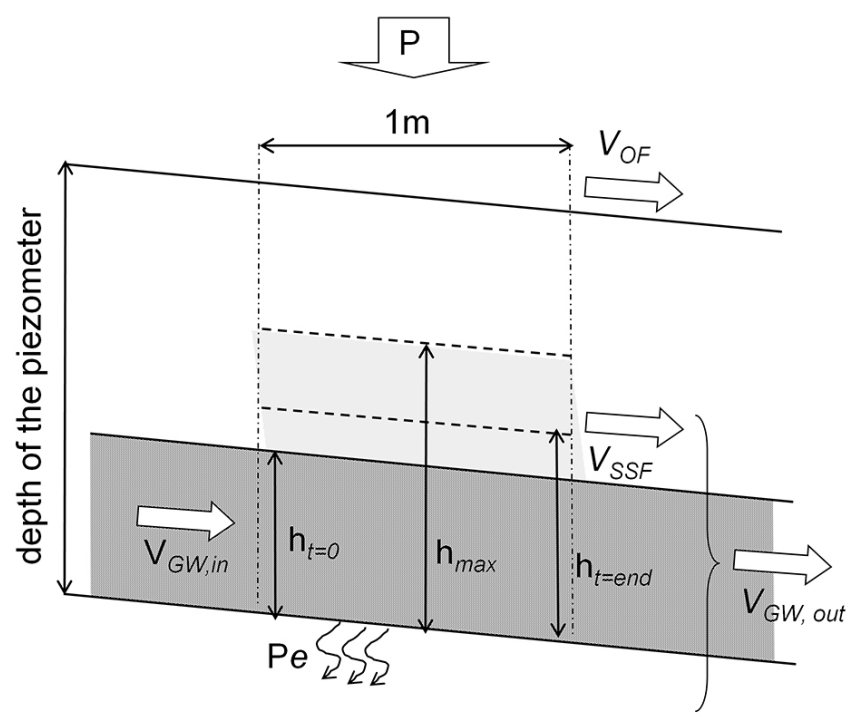

Figure 4. Schematic representation of water balance components of experimental plots. $\mathrm{P}$ is sprinkling volume; $V_{\mathrm{OF}}$ is volume of overland flow; $V_{\mathrm{SSF}}$ is volume of subsurface flow; Pe is volume of "deep percolation"; $V_{\mathrm{GW}}$, in and $V_{\mathrm{GW}}$,out are volumes of groundwater inflow and outflow, respectively; $h_{t}$ is the groundwater level at time $t(t=0$ - just before the sprinkling starts; $t=$ end - at the end of sprinkling experiment); and $h_{\max }$ is maximal groundwater level observed during sprinkling experiment.

The tracer mass balance analysis was performed in order to evaluate the assumption of water mobility and full mixing within the soil column. The bromide and chloride masses were calculated from the chemical measurements and corresponding water volumes. The tracer mass remaining in the soil column was calculated in two ways: (1) based on the tracer mass balance, and (2) based on the measured tracer concentration in the groundwater at the end of the sprinkling experiments. The differences between the two allowed us to evaluate the mixing assumption. The percentage of the experimental area that is hydrologically active $(x)$ was estimated based on the following equation:

$$
\begin{aligned}
& C_{\mathrm{Br}^{-} / \mathrm{Cl}^{-}}\left(t_{\mathrm{end}}\right) \cdot V\left(t_{\mathrm{end}}\right)=x \cdot C_{\mathrm{Br}^{-} / \mathrm{Cl}^{-}, \mathrm{PE}} \cdot V_{\mathrm{PE}} \\
& +C_{\mathrm{Br}^{-} / \mathrm{Cl}^{-}, \mathrm{EW}} \cdot V_{\mathrm{INF}}-x \cdot C_{\mathrm{Br}^{-} / \mathrm{Cl}^{-}}(t) \cdot V_{\mathrm{SSF}} \\
& V\left(t_{\mathrm{end}}\right)=x \cdot V_{\mathrm{PE}}+V_{\mathrm{INF}}-x \cdot V_{\mathrm{SSF}} .
\end{aligned}
$$

It is important to note that $V_{\mathrm{PE}}$ and $V_{\mathrm{SSF}}$ were estimated based on groundwater level observation multiplied by the (hydrologically active) area of the experiment.

Table 2 shows tracer mass balance component and is subdivided into two parts: first, the results based on the assumption that the whole soil column is hydrologically active (i.e. full mixing), and second, the results taking into account a percentage of the soil column that is hydrologically active.

Furthermore, the influence of porosity values was evaluated. Increasing or decreasing the average porosity by 0.01 and 0.02 results in changes in the water balance components. The influence of porosity on the estimated volume of preevent water was limited: no changes in plot A (since there was no groundwater before the experiment), $\pm 5 \%$ in plot B and $\pm 3 \%$ in plot $\mathrm{C}$. The volume of subsurface flow is more sensitive for changes in soil porosity. It varies between $\pm 35 \%$ in plot A and $\pm 24 \%$ in plot C. Within plot B the change in subsurface flow volume, expressed as a percentage, is also significant (between +11 and $-55 \%$ ), but it corresponds to relatively low absolute values $\left(0.05-0.1 \mathrm{~m}^{3}\right)$. Consequently, the changes in volume of water stored in the soil column at the end of the experiment are the highest for plot A (between -23 and $+44 \%)$ and relatively limited for plot B $( \pm 7 \%)$ and plot $C( \pm 14)$. The influence of porosity changes on the calculated percentage of hydrologically active area (Eq. 6) is limited to a maximum of $\pm 2 \%$. 

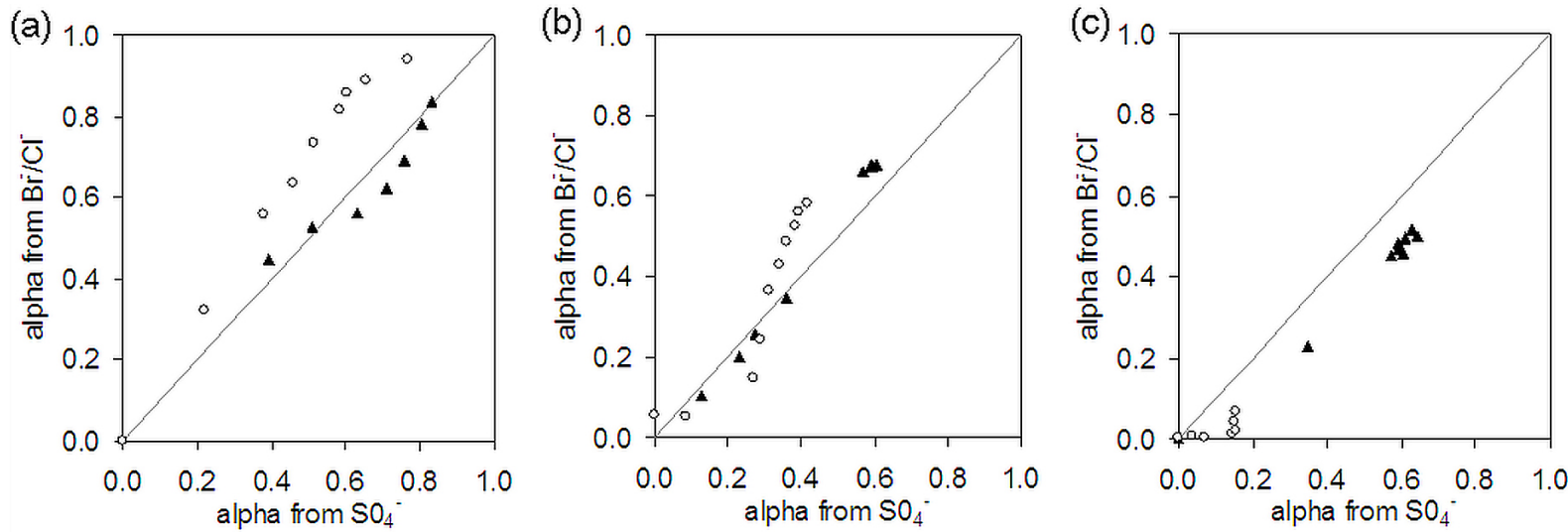

Figure 5. EMMA model results for the centrally located piezometers A1 (a), B1 (b) and C1 (c). The full triangles are estimates for the first day of the experiment and the open dots represents second day of the experiment. The grey line is the $1: 1$ line.

\subsection{Hydrological and hydrochemical observation}

A diverse spectrum of results clearly emerges from the experiments. However, the results also show interesting similarities. The sprinkling water infiltrates into the top soil through both matrix and preferential (fissure) flow paths. Once water enters into the soil the plots essentially show two types of drainage. First, groundwater level depletes quickly and slows down after 15-90 min. Interestingly, fast infiltration and fast drainage do not coincide. Plot A has both fast infiltration and fast drainage (both in first and second stage), whereas plot B shows high infiltration capacity and the second reservoir shows the slowest depletion of the stored subsurface water. Plot $\mathrm{C}$ has a low infiltration rate but seems to drain the infiltrated water relatively smoothly.

The tracer information shows similarities with the groundwater patterns. Both bromide and chloride concentrations rise, almost reaching the initial concentration of the sprinkling in the centre of plot A and around $60 \%$ of the initial concentration of the sprinkling in the centre of plot $\mathrm{B}$ within the duration of the experiment. In plot $\mathrm{C}$ both tracers reach a maximum of $50 \%$ relative concentration, indicating more mixing with pre-event water. The location of highest relative concentration is in the centre for plot $\mathrm{A}$ and downslope of plot $\mathrm{B}$ (in B3). Plot $\mathrm{C}$ results are again a bit more diverse: both piezometers $\mathrm{C} 1$ and $\mathrm{C} 2$ show mixing of sprinkling water with pre-event water for the first day, but only $\mathrm{C} 2$, located downslope, shows a significant increase of chloride concentration during the second day experiment.

The results of the EMMA model underline the differences in mixing processes and their dynamics observed at each plot (Fig. 5). For all plots the relation between mixing proportions estimated based on both applied tracer and sulfate concentrations do not follow the $1: 1$ line exactly. This can be an effect of soil-water interaction (dissolution of pyrite). This can be partly due to the uncertainty on the estimates of PE sulfate concentrations, which may substantially vary over short distances. Within plot A and B the mixing processes are clear: the mixing proportions change progressively during the sprinkling experiment from $0 \%$ to more than $90 \%$ (plot A), or around $70 \%$ (plot B) for both tracers and sulfate. In plot $\mathrm{C}$ the mixing proportions increase during the first day but are limited to $64 \%$. Moreover, in plot A and $\mathrm{B}$, the artificial and environmental tracers behave similarly over the 2 days of sprinkling experiment, showing that mixing processes can be explained with two end members only: mixing of event water with pre-event water. This is also the case for the first day in plot C. During the second day of the experiment, a sharp dilution of sulfate was observed in $\mathrm{C} 1$, while the $\mathrm{Cl}^{-}$concentration remained low and the $\mathrm{Br}^{-}$concentration increased. This indicates that in plot $\mathrm{C}$, both event waters (EW1 during first day and EW2 during second day of sprinkling) contributed independently in mixing with preevent water. However, it is important to stress that EMMA results are based only on tracer concentrations and give a relative mixing proportion and do not give the absolute mass of the mixed tracers.

The three plots show different spatial responses. In the case of plot $\mathrm{A}$, three piezometers show a response in water level and in tracer concentration. In plots B and C only two piezometers react to the sprinkling in groundwater level and water quality. This suggests that plots $\mathrm{B}$ and $\mathrm{C}$ have structured flow paths whereas plot A is more permeable in all directions. Subsurface flow often follows the slope gradient; however, the presence of fissures and macroporosity (plot A and B) strongly influence flow direction.

Based on the interpretation of the sprinkling experiment, three types of hydrological behaviour are identified:

- Fast input, fast output (plot A) and very fast infiltration as well as fast drainage.

- Fast input, slow output (plot B) and fast infiltration but very slow drainage. 
Table 2. Measured $\left({ }^{\mathrm{m}}\right)$ and estimated $\left({ }^{\mathrm{e}}\right)$ tracer mass balance components and the evaluation of the hydrologically active area assumptions.

\begin{tabular}{|c|c|c|c|c|c|c|}
\hline \multirow[b]{2}{*}{ Day of experiment (applied tracer) } & \multicolumn{2}{|c|}{ Plot A } & \multicolumn{2}{|c|}{ Plot B } & \multicolumn{2}{|c|}{ Plot C } \\
\hline & 1st $\left(\mathrm{Br}^{-}\right)$ & 2nd $\left(\mathrm{Cl}^{-}\right)$ & 1st $\left(\mathrm{Br}^{-}\right)$ & 2nd $\left(\mathrm{Cl}^{-}\right)$ & 1st $\left(\mathrm{Br}^{-}\right)$ & 2nd $\left(\mathrm{Cl}^{-}\right)$ \\
\hline \multicolumn{7}{|l|}{ Tracer in applied water } \\
\hline$-^{(\mathrm{m})}$ concentration, []$_{\mathrm{EW}}\left[\mathrm{g} \mathrm{m}^{-3}\right]$ & 118 & 1035 & 122 & 128 & 123 & 1047 \\
\hline$-{ }^{(\mathrm{e})} \operatorname{mass}[\mathrm{g}]$ & 32.3 & 343.7 & 44.1 & 53.5 & 35.6 & 322.5 \\
\hline${ }^{(\mathrm{e})}$ Infiltrated tracer $[\mathrm{g}]$ & 32.3 & 343.7 & 44.1 & 53.5 & 10.1 & 82.5 \\
\hline \multicolumn{7}{|c|}{ assuming that whole area is hydrologically active } \\
\hline (e) Tracer out of soil column via & \multirow{2}{*}{\multicolumn{2}{|c|}{ Not observed }} & \multirow{2}{*}{\multicolumn{2}{|c|}{ Not observed }} & & \\
\hline - overland flow, $[\mathrm{g}]$ & & & & & 22.3 & 237.3 \\
\hline - subsurface flow, $[\mathrm{g}]$ & $-^{*}$ & 162.8 & $>33^{* *}$ & 36.2 & 4.2 & 2 \\
\hline (e) Mass of tracer remaining in soil column & & & & & & \\
\hline $\begin{array}{l}\text { based on mass budget }[\mathrm{g}]\left(\text { mass }_{\text {in }}-\text { mass }_{\text {out }}\right) \\
(\mathrm{m}) \text { Tracer concentration in the }\end{array}$ & $-^{*}$ & 180.9 & $<11.1$ & 17.3 & 5.9 & 82.6 \\
\hline $\begin{array}{l}\text { groundwater, [ ] }\left(t_{\mathrm{end}}\right)\left[\mathrm{g} \mathrm{m}^{-3}\right] \\
\text { (e) Mass of tracer remaining in soil column }\end{array}$ & 91.4 & 768.5 & 81.4 & 73.6 & 45.8 & 50.34 \\
\hline $\begin{array}{l}\text { based on measured concentration, [g] } \\
\left(V\left(t_{\text {end }}\right) \times[]\left(\left(t_{\text {end }}\right)\right)\right.\end{array}$ & $--^{*}$ & 261.3 & 27.7 & 25.8 & 35.7 & 39.7 \\
\hline
\end{tabular}

assuming that $x$ percentage of the area is hydrologically active

\begin{tabular}{|c|c|c|c|c|c|c|}
\hline \multicolumn{7}{|l|}{ (e) Percent of the plot area that is } \\
\hline $\begin{array}{l}\text { hydrologically active, } x[\%] \\
\text { (e) Tracer out of the soil column }\end{array}$ & $-^{*}$ & 53 & 24 & 60 & 17 & 210 \\
\hline $\begin{array}{l}\text { via subsurface, }[\mathrm{g}] \\
\text { (e) Mass of tracer remaining in soil column }\end{array}$ & $-^{*}$ & 86.3 & $>25.7^{* *}$ & 34.2 & $0.7^{* *}$ & 4.3 \\
\hline $\begin{array}{l}\text { based on mass budget }[\mathrm{g}] \\
\text { (e) Mass of tracer remaining in soil column }\end{array}$ & $-{ }^{*}$ & 257.4 & $<18.4^{* *}$ & 19.3 & $9.4 * *$ & 82.7 \\
\hline based on measured concentration, $[\mathrm{g}]$ & $-^{*}$ & 257.7 & 18.4 & 18.9 & 9.5 & 80.8 \\
\hline
\end{tabular}

measured only from the third hour of the sprinkling experiment.

- Fast but limited input, moderate output (plot C), limited infiltration and relatively slow drainage (when compared with plot A).

\subsubsection{Flow regime 1: fast input-fast output}

Plot A represents a fast input-output type of hydrological response: a very fast response to the onset of sprinkling, as well as a sudden groundwater level drop after the sprinkling has finished. The sharp groundwater level decrease in A1 (see Fig. 3) after the end of the sprinkling test is an indication of drainage from a highly permeable fraction of the subsurface, e.g. the fissure fraction. Moreover, the second part of the depletion curve is quite rapid as well, indicating that the matrix fraction is also highly permeable. The very high permeability is confirmed by the fact that groundwater responses are observed not only in the centre of the experimental plot (A1) but also in two directions downslope: relatively quick response in $\mathrm{A} 3$ (direction of fissures observed on the surface) and delayed in $\mathrm{A} 2$.

There is $0.7 \mathrm{~m}^{3}$ of pre-event water (approximately 33$36 \%$ of maximal storage capacity) storage in the soil col- umn. Of this pre-event water, 50-54\% could mix and readily move with the infiltrating sprinkling water (Tables 1 and 2). The incident with the accidental application of high concentration $\mathrm{Br}^{-}$at the beginning of the second day demonstrates the dominance of fast preferential flow through the plot and short residence times of water within the soil column.

\subsubsection{Flow regime 2: fast input-slow output}

The hydrological responses in plot B can be described as fast input-delayed output. The presence of a largely open (up to $14 \mathrm{~cm}$ ) fissure system influences the distribution of infiltrating water. However, more than $70 \%$ of the infiltrated water is flowing out of the soil column and exfiltrating downslope. The observed hydrological response is a combination of fast vertical infiltration, fast subsurface flow and much slower matrix flow. The shape of the drawdown curve (Fig. 3) also indicates the combination of mainly preferential flow with some matrix flow.

The behaviour of the tracer concentration indicates complex mixing processes in plot $\mathrm{B}$. The changes in the $\mathrm{Br}^{-}$and $\mathrm{Cl}^{-}$concentration also show that infiltrating water of the first 
day replaced the pre-event water and is temporarily stored until the new source of water (sprinkling of second day) appears. The relatively low concentration of tracer in $\mathrm{B} 1$ shows that a significant amount of pre-event water (approximately $80-84 \%$ of maximum storage) is stored in the matrix and $24-61 \%$ of this water is involved in the mixing process (Tables 1 and Table 2). The spatial distribution of tracer concentration (lower concentration in B1; higher in B3 and in subsurface flow) indicates a well-structured subsurface (including fissure system) which can provide direct drainage for infiltrated water. The fast flow domain is isolated from the matrix (no or poor connection). When the groundwater level is high, a well-connected preferential flow system becomes active and the applied water drains directly $\left(K_{1, B}\right.$; Fig. 3$)$. However, once the water level has dropped by several centimetres, the drainage stops (e.g. dead-end fissure) and the system maintains high groundwater levels for several hours $\left(K_{2, B}\right.$; Fig. 3). The last drainage phase $\left(K_{3, B}\right.$; Fig. 3) can be interpreted as matrix flow occurring after saturation, connecting the wet fissure areas.

\subsubsection{Flow regime 3: fast-but-limited input-moderate out- put}

The general observation of the water balance component (Table 1) and drawdown curves (Fig. 3) indicates that plot C represents a matrix-like infiltration behaviour; however, the influence of preferential flow cannot be neglected. A significant drainage at the end of each 15 min sprinkling block and a depletion almost 3 times higher in the steep part of the depletion curve $\left(K_{1 C}\right)$ with respect to the gentle slope part $\left(K_{2 C}\right)$ indicate the presence of preferential flow paths (fissures, macropores), which influence the hydrological behaviour at studied scale.

There is a significant amount of pre-event water (approximately $92-94 \%$ of maximum storage) is stored in the soil column. The tracer mass balance for the first day of the experiment (Table 2) indicates that only around $16-18 \%$ of the pre-event water stored in the subsurface is actively mixed with the infiltrated sprinkling water. The opposite conclusion can be drawn when analysing the mass balance for the second day of the sprinkling experiment. Under the assumption that all infiltrated sprinkling water is stored in the $1 \times 1 \mathrm{~m}^{2}$ plot, a double amount of pre-event water should be involved in the mixing processes in order to match the measured $\mathrm{Cl}^{-}$ concentration in $\mathrm{C} 1$. However, the concentrations of $\mathrm{Cl}^{-}$in $\mathrm{C} 2$ (located outside the sprinkling plot) indicate that there is a significant amount of tracer stored outside the experimental plot, due to surface ponding and subsurface water flow. Moreover, assuming that the hydrologically active area during the second day of experiment is the same as during the first day of experiment (around 20\%), only 1-2\% of infiltrated tracer mass is enough to reach the measured tracer concentration in the groundwater at the end of experiment. This indicates the presence of preferential drainage. Nevertheless, the presence of $\mathrm{Br}^{-}$in $\mathrm{C} 1$ (middle of the sprinkling plot) during the second day, when only $\mathrm{Cl}^{-}$was applied, confirms that matrix flow dominates in the area and that piston flow processes occurred. The rise of the $\mathrm{Br}^{-}$concentration, both in $\mathrm{C} 1$ and $\mathrm{C} 2$, observed at the beginning of the second day of sprinkling might be explained by the tracer settling over soil surface during water ponding on the first day of sprinkling and being mobilised by "new" sprinkled water.

\subsection{Discussion of conceptual models for the Super-Sauze landslide}

The improvement of hydrological modelling of the SuperSauze landslide is not a direct aim of this paper: the small number of sprinkling experiments and their small scale in relation to the landslide area of 0.17 ha are not sufficient to cover the whole landslide. Therefore, the results cannot yet be up-scaled to a complete distributed hydrological model of the landslide.

However, the components of the hydrological system, identified based on small-scale sprinkling tests, are in line with the conceptual model of the Super-Sauze landslide proposed by Malet et al. (2005) and de Montety et al. (2007). The former proposed a distributed conceptual model of the hydrological behaviour of the Super-Sauze landslide dividing the landslide into three hydro-geomorphological units (Fig. 1a). The upper unit (HG1), where plot $A$ and $B$ are located, is very active and characterised by very rapid responses and large groundwater level fluctuation (up to $0.5 \mathrm{~m}$ ) at the event scale. The western part of upper unit (HG3), where plot $\mathrm{C}$ is located, is the most stable part of the landslide, with very limited groundwater level fluctuation (centimetres). Our results confirm this hydrological concept, but they also stress clear differences in the hydrological response in the upper unit (Fig. 6), which was not presented as clearly by Malet et al. (2005). However, it is important to note that the hydrochemical behaviour observed in plot $\mathrm{C}$ is strongly influenced by the presence of small fissures and cannot be compared with general the hydrological concept of Malet et al. (2005).

The hydrological interpretation of the Super-Sauze landslide presented by de Montety et al. (2007), based on the long-term observation of spatial distribution of major cations and anions, defines dominant hydrological processes along the landslide profile. The upper part of the landslide (directly below the main scarp) is the "transition" zone, while the middle part of the landslide is dominated by preferential flow. This is in agreement with our observed fast input-fast output behaviour in plot $\mathrm{A}$ and fast input-slow output behaviour in plot B. The stable part of the landslide, where plot $\mathrm{C}$ was located, was not considered in the work of de Montety et al. (2007). De Montety et al. (2007) stressed the limitation of their investigation having only a qualitative assessment of the water fluxes and underlined the need for more detailed investigations. Our experiments show the potential for more 


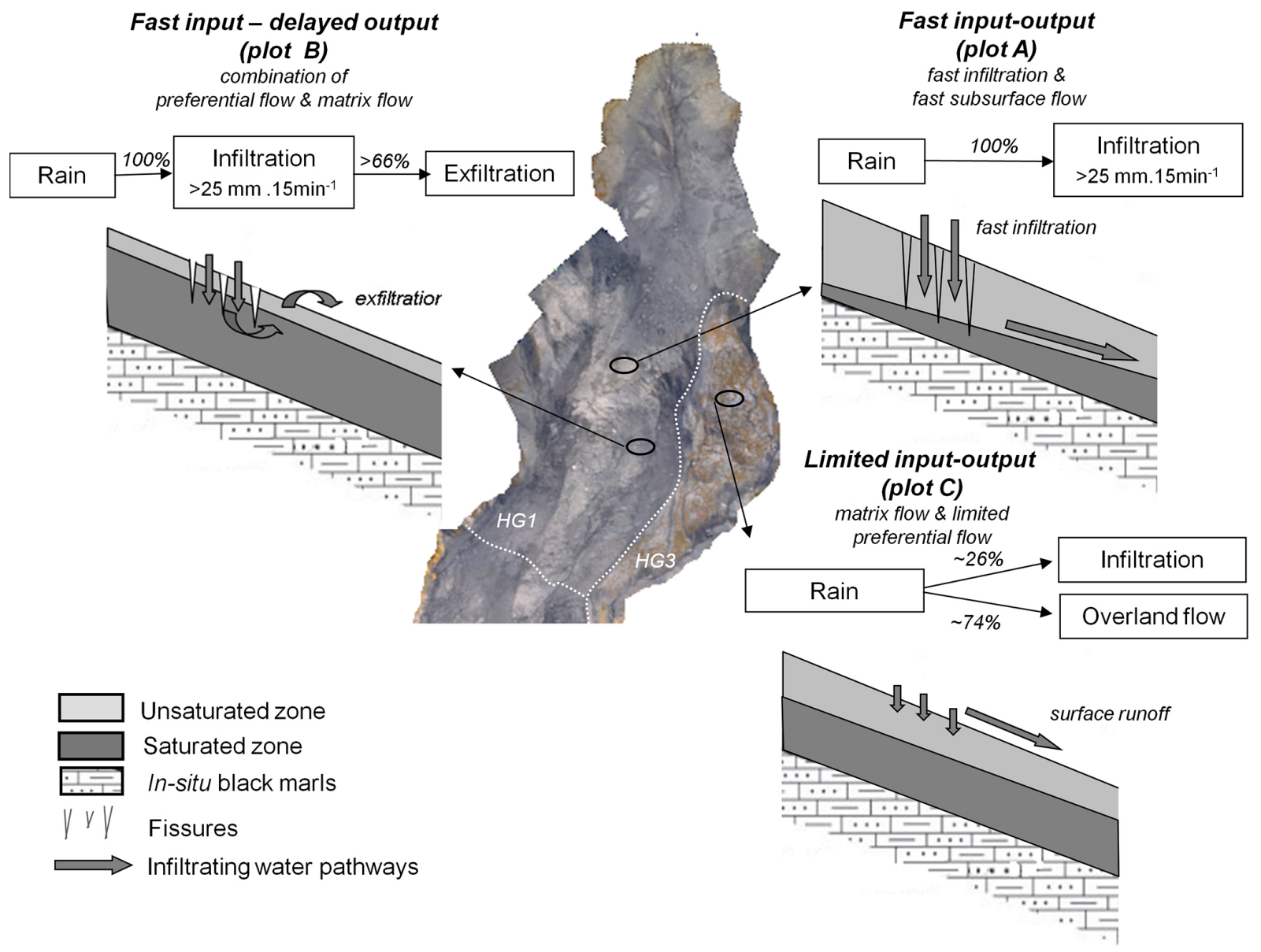

Figure 6. Flow regimes derived from hydrological and hydrochemical analysis of small-scale sprinkling experiment and their distribution across the upper part of the Super-Sauze landslide. The white dashed lines indicate the hydro-geomorphological (HG) units defined by Malet et al. (2005).

quantitative analyses of the components of the hydrological processes acting on the landslide and possible extension of the conceptual model with the identification of surface hydrological processes such as exfiltration and runoff.

Finally, our results are comparable with the large-scale sprinkling experiment performed previously in the area where plot B was located at the Super-Sauze landslide (Debieche et al., 2012). They confirm that hydrodynamic and hydrochemical responses cannot be fully inferred from surface area characteristics only. The sprinkling water infiltrates into the soil both through the matrix and preferential flow paths. The groundwater flow follows the overall slope direction, but the presence of fissures and subsurface structures strongly influences the exact direction of the subsurface water flow. Furthermore, unweathered marly blocks, characterised by relatively low permeability, decrease the percolation rate and create areas of limited hydrological activity.

\subsection{Broader implications for landslide studies}

Our findings outline the spatial heterogeneity existing in slow-moving slopes due to the interaction between displacements and hydraulic properties of the soil and thus hydrological behaviour. They reflect clear different topographic features in the landslide mass (i.e. the hydro-geomorphic units including fissure types). Linking the knowledge of geomorphological landslide development (e.g. Travelletti and Malet, 2012) with a hydrological characterisation derived by the small-scale hydrological and hydrochemical sprinkling experiments seems a logical next step. Secondary mass movements, like a local mudflow or landslide on the overall slowmoving landslide, will change the local hydrological regime. However, how long this processes would last and how they would (re-)develop over time is hard to say. Hereto the sprinkling experiments should be spatially distributed, but should as well be redone after major displacement events. Our limited set of experiments and observations does not allow for far-reaching conclusions on the relationship between hydrological regime and landslide development. However, it is 
tempting to speculate on it: as displacements in a landslide occur, the moving mass changes/adapts its hydraulic properties and, consequently, the pore pressure field. This influences the geomechanical behaviour of the moving mass: it could stabilise the mass due to drainage, but could also result in acceleration due to excess pore pressure during transient undrained condition. These feedbacks and the interplay of processes seem very relevant for the behaviour of a slope or landslide. This constitutes an example of how to study the coevolution of landscape development and hydrology, as advocated in recent studies on catchment hydrology (Ehret et al., 2014).

\section{Conclusions}

This paper shows the potential of combined hydrological and hydrochemical analyses by means of small-scale $1 \times 1 \mathrm{~m}^{2}$ sprinkling experiments for studying the spatial differences in hydrological response to precipitation input. The approach was applied at the specific environment of the highly heterogeneous Super-Sauze landslide (French Alps).

Dual or multiple permeability systems can be found in many hillslopes and they steer the hydrological dynamics of the hillslope. In such cases, laboratory tests for characterising hydraulic soil parameters are insufficient and in situ measurements or experiments are necessary. Small-scale sprinkling experiments performed with the use of artificial tracers and in situ observations of hydrological and hydrochemical response showed to be very effective in unravelling complex hydrological systems. A 2-day sprinkling experiment also had the clear advantage of allowing for more in-depth analyses of mixing processes to be performed (pre-eventinfiltrated water). These analyses confirmed that the presence of fissures increases the vertical infiltration rate and controls the direction of subsurface water flow (e.g. McDonnell, 1990; Uchida et al., 2001). Furthermore, our results support the concept that antecedent water storage influences the initiation of preferential flow, as found, for example, in Trojan and Linden (1992), Zehe and Fluhler (2001) and Weiler and Naef (2003).

Presented experiments are relatively inexpensive, can be deployed throughout the landslide area and do not need longterm monitoring programmes. This paves the road for more widespread applications in order to better understand the spatial differences and similarities of hydrological processes across a landslide area. In order to extend the application of small-scale sprinkling experiments and to overcome current shortcomings, the following should be considered:

- detailed measurements of soil characteristics, their heterogeneity in the analysed soil profile, and their high temporal resolution monitoring during the sprinkling experiment;
- applying non-destructive measures to provide more detailed characteristics of subsurface fissure system, especially in vertical directions. Grandjean et al. (2012) and Travelletti et al. (2012) presented promising results based on seismic azimuth tomography or ERT measurements. However, both methodologies need further improvement to provide the unique characteristics of subsurface flow paths.

Although we performed only a limited amount of experiments, we showed that small-scale sprinkling experiments were capable of capturing and monitoring the hydrological processes across the landslide. Additionally, they show a potential for quantifying subsurface flow processes.

Acknowledgements. This work was supported by the European Commission within the Marie Curie Research and Training Network "Mountain Risks: from prediction to management and governance" (2007-2010, contract MCRTN-035798) and by the French National Research Agency (ANR) within the project "Ecou-Pref-Ecoulements préférentiels dans les versants marneux" (contract ANR05-ECCO-007-04).

Edited by: V. Vanacker

\section{References}

Allaire-Leung, S. E., Gupta, S. C., and Moncreif, J. F. : Water and solute movement in soil as influenced by macropore characteristics: I. Macropore continuity, J. Contamin. Hydrol., 41, 283-301, 2000.

Allaire S. E., Roulier S., and Cessna A. J. : Quantifying preferential flow in soils: a review of different techniques, J. Hydrol., 378, 179-204, 2009.

Anderson, L.: Fracture Mechanics: Fundamentals and Applications, 3rd Edition, Taylor \& Francis, 2005.

Angulo-Jaramillo, R., Gaudet, J.-P., Thony, J.-L., and Vauclin, M.: Measurement of hydraulic properties and mobile water content of a field soil, Soil Sci. Soc. Am. J., 60, 710-715, 1996.

Beven, K. and Germann, P.: Macropores and water flow in soils, Water Resour. Res., 18, 1311-1325, 1982.

Bogaard, T. A., Buma, J. T., and Klawer, C. J. M.: Testing the potential of geochemical techniques for identifying hydrological systems within landslides in partly weathered marls, Geomorphology, 58, 323-338, 2004.

Boll, J., Steenhuis, T. S., and Selker, J. S.: Fiberglass wicks for sampling of water and solutes in the vadose zone, Soil Sci. Soc. Am. J., 56, 701-707, 1992.

Christophersen, N. and Hooper, R. P.: Multivariate analysis of stream water chemical data - the use of principal component analysis for the end-member mixing problem, Water Resour. Res., 28, 99-107, 1992.

Coe, J. A., Michael, J. A., Crovelli, R. A., Savage, W. Z., Laprade, W. T., and Nashem, W. D.: Probabilistic assessment of precipitation-triggered landslides using historical records of landslide occurrence, Seattle, Washington, Environ. Engin. Geosci., 10, 103-122, 2004. 
Collins, R., Jenkins, A., and Harrow, M.: The contribution of old and new water to a storm hydrograph determined by tracer addition to a whole catchment, Hydrol. Proc., 14, 701-711, 2000.

Cras, A., Marc, V., and Travi, Y.: Hydrological behaviour of subMediterranean alpine headwater streams in a badlands environment, J. Hydrol., 339, 130-144, 2007.

Debieche, T.-H., Bogaard, T. A., Marc, V., Emblanch, C., Krzeminska, D. M., and Malet, J.-P.: Hydrological and hydrochemical processes observed during a large-scale infiltration experiment at the Super-Sauze mudslide (France), Hydrol. Proc., 26, 2157-2170, 20112.

De Montety, V., Marc, V., Emblanch, C., Malet, J.-P., Bertrand, C., Maquaire, O., and Bogaard, T. A. : Identifying the origin of groundwater and flow processes in complex landslides affecting black marls: insights from a hydrochemical survey, Earth Surface Proc. Land., 32, 32-48, 2007.

Ehret, U., Gupta, H. V., Sivapalan, M., Weijs, S. V., Schymanski, S. J., Blöschl, G., Gelfan, A. N., Harman, C., Kleidon, A., Bogaard, T. A., Wang, D., Wagener, T., Scherer, U., Zehe, E., Bierkens, M. F. P., Di Baldassarre, G., Parajka, J., Van Beek, L. P. H., Van Griensven, A., Westhoff, M. C., and Winsemius, H. C.: Advancing catchment hydrology to deal with predictions under change, Hydrol. Earth Syst. Sci., 18, 649-671, 2014,

http://www.hydrol-earth-syst-sci.net/18/649/2014/.

Flury, M., Fluhler, H., Jury, W. A., and Leuenberger, J.: Susceptibility of soils to preferential flow of water: a field study, Water Resources Research, 30, 1945-1954, 1994.

Garel, E., Marc, V., Ruy, S., Cognard-Plancq, A.-L., Klotz, S., Emblanch, C., and Simler, R.: Large scale rainfall simulation to investigate infiltration processes in a small landslide under dry initial conditions: the Draix hillslope experiment, Hydrol. Proc., 26, 14 pp., doi:10.1002/hyp.9273, 2012.

Grandjean, G., Bitri, A., and Krzeminska, D.M.: Characterisation of a landslide fissure pattern by integrating seismic azimuth tomography and geotechnical testing, Hydrol. Proc., 26, 2120-2127, 2012

Greco, R.: Preferential flow in macroporous swelling soil with internal catchment, model development and applications, J. Hydrol., 269, 150-168, 2002.

Gerke, H. H.: Preferential flow descriptions for structured soils, J. Plant Nutrit. Soil Sci., 169, 382-400, 2006.

Gwo, J. P., Jardine, P. M., Wilson, G. V., and Yeh, G. T.: A multiplepore-region concept to modeling mass transfer in subsurface media, J. Hydrol., 164, 217-237, 1995.

Haneberg, W. C.: Observation and analysis of short-term pore pressure fluctuations in a thin colluvium landslide complex near Cincinnati, Ohio, Engin. Geol., 31, 159-184, 1991.

Hornberger, G. M., German, P. F., and Beven, K. J.: Throughflow and solute transport in an isolated sloping soil block in a forested catchment, J. Hydrol., 124, 81-99, 1991.

IA PAS: Manual for Field Operated Meter (FOM), Institute of Agrophysics, Polish Academy of Science Lublin, 1-34, 2006.

James, A. L. and Roulet, N. T.: Investigating the applicability of end-member mixing analysis (EMMA) across scale: A study of eight small, nested catchments in a temperate forested watershed, Water Resour. Res., 42, 8, doi:10.1029/2005WR004419, 2006.

Jarvis, N. J.: A review of non-equilibrium water flow and solute transport in soil macropores: principles, controlling factors and consequences for water quality, European Journal of Soil Science, 58, 523-546, 2007.

Kabeya, N., Katsuyama, M., Kawasaki, M., Ohte, N., and Sugimoto, A.: Estimation of mean residence times of subsurface waters using seasonal variation in deuterium excess in a small headwater catchment in Japan, Hydrol. Proc., 21, 308-322, 2007.

Kienzler, P. and Naef, F.: Temporal variability of subsurface stormflow formation, Hydrol. Earth Syst. Sci., 12, 257-265, 2008, http://www.hydrol-earth-syst-sci.net/12/257/2008/.

Kirchner, J. W.: A double paradox in catchment hydrology and geochemistry, Hydrol. Proc., 17, 871-874, 2003.

Larsbo, M. and Jarvis, N.: Information content of measurements from tracer microlysimeter experiments designed for parameter identification in dualpermeability models, J. Hydrol., 325, 273287, 2006.

Linsley, R. K., Kohler, M. A. and Paulhus, J. L. H.: Hydrology for Engineers, Third Edition, New York, McGraw-Hill Book Company, 1982.

Malet, J.-P., Maquaire, O., and Calais, E.: The use of Global Positioning System techniques for the continuous monitoring of landslides: application to the Super-Sauze earthflow (Alpes-deHaute-Provence, France), Geomorphology, 43, 33-54 2002.

Malet, J.-P.: Les glissements de type écoulement dans les marnes noires des Alpes du Sud. Morphologie, fonctionnement et modélisation hydro-mécanique, Ph.D. thesis, Université Louis Pasteur, Strasbourg, 2003.

Malet, J.-P., Auzet, A. V., Maquaire, O., Ambroise, B., Descroix, L., Esteves, M., Vandervaere, J. P., and Truchet, E.: Soil surface characteristics influence on infiltration in black marls: application to the Super-Sauze earthflow (Southern Alps France), Earth Surf. Proc. Landf., 28, 547-564, 2003.

Malet, J.-P., van Asch, T. W. J., van Beek, L. P. H., and Maquaire, O.: Forecasting the behaviour of complex landslides with a spatially distributed hydrological model, Natural Haz. Earth Syst. Sci., 5, 71-85, 2005.

Mali, N., Urbanc, J., and Leis, A.: Tracing of water movement through the unsaturated zone of a coarse gravel aquifer by means of dye and deuterated water, Environ. Geol., 51, 1401-1412, 2007.

McDonnell, J. J.: The influence of macropores on debris flow initiation, Quarterly J. Engin. Geol. Hydrogeol., 23, 325-331, 1990.

Mikovari, A., Peter, C., and Leibundgut, Ch.: Investigation of preferential flow using tracer techniques, in: Tracer Technologies for Hydrological Systems, Proceedings of a Boulder Symposium, July 1995, 1995.

Mulholland, P. J. and Hill, W. R.: Seasonal patterns in streamwater nutrient and dissolved organic carbon concentrations: Separating catchment flow path and in-stream effects, Water Resour. Res., 33, 1297-1306, 1997

Niethammer, U., James, M. R., Rothmund, S., Travelletti, J., and Joswig, M.: UAV-based remote sensing of the Super-Sauze landslide: Evaluation and results, Engin. Geol., 128, 2-11, 2012.

Pierson, T. C.: Soil pipes and slope stability, Quart. J. Engin. Geol., 16, 1-15, 1983.

Savage, W. Z., Godt, J. W. and Baum, R. L.: A model for spatially and temporally distributed shallow landslide initiation by rainfall infiltration, in: Proceedings of the third international conference on debris flow hazards mitigation: mechanics, prediction, and as- 
sessment, edited by: Rickenmann, D. and Chen, C.-L., Davos, Millpress, Rotterdam, 179-187, 2003.

Schulson, E. M. and Duval, P.: Creep and Fracture of Ice, Cambridge University Press, New York, 2009.

Šimůnek, J., Jarvis, N. J., van Genuchten, M. T., and Gardenas, A.: Review and comparison of models for describing nonequilibrium and preferential flow and transport in the vadose zone, J. Hydrol., 272, 14-35, 2003.

Sivapalan, M., Jothityangkoon, C., and Menabde, M.: Linearity and nonlinearity of basin response as a function of scale: discussion of the alternative definitions, Water Resour. Res., 38, 2, doi:10.1029/2001WR000482, 2002.

Soulsby, C., Rodgers, P., Smart, R., Dawson, J., and Dunn, S.: A tracer-based assessment of hydrological pathways at different spatial scales in a mesoscale Scottish catchment, Hydrol. Proc., 7, 759-777, doi:10.1002/hyp.1163, 2003.

Stumpf, A., Malet, J.-P., Kerle, N., Niethammer, U., and Rothmund, S.: Image-based mapping of surface fissures for the investigation of landslide dynamics, Geomorphology, 15, 12-27, 2012.

Travelletti, J. and Malet, J.-P.: Characterization of the 3D geometry of flow-like landslides: A methodology based on the integration of heterogeneous multi-source data, Engeen. Geol., 128, 30-48, 2012

Travelletti, J., Sailhac, P., Malet, J.-P., Grandjean, G., and Ponton, J.: Hydrological response of weathered clay-shale slopes: water infiltration monitoring with time-lapse electrical resistivity tomography, Hydrol. Proc., 26, 2106-2119, 2012.

Trojan, M. and Linden, D.: Micro relief and rainfall effects on water and solute movement in eartchworm burrows, Soil Sci. Soc. Am. J., 56, 727-733, 1992.

Tromp-van Meerveld, H. J. and McDonnell, J. J.: Threshold relations in subsurface stormflow: 2. the fill and spill hypothesis, Water Resour. Res., 42, 3, doi:10.1029/2004WR003778, 2006.
Uchida, T., Kosugi, K., and Mizuyama, T.: Effects of pipeflow on hydrological process and its relation to landslide: a review of pipeflow studies in forested headwater catchments, Hydrol. Proc., 15, 2151-2174, 2001

Walter, M., Arnhardt, C., and Joswig, M.: Seismic monitoring of rockfalls, slide quakes, and fissure development at the SuperSauze mudslide, French Alps, Engin. Geol., 128, 12-22, 2012.

Weiler, M. and Naef, F.: An experimental tracer study of the role of macropores in infiltration in grassland soils, Hydrol. Proc., 17, 477-493, 2003.

Weiler, M. and McDonnell, J. J.: Conceptualizing lateral preferential flow and flow networks and simulating the effects on gauged and ungauged hillslopes, Water Resour. Res., 43, 3, doi:10.1029/2006WR004867, 2007.

Wienhöfer, J., Lindenmaier, F., and Zehe, E.: Challenges in Understanding the Hydrologic Controls on the Mobility of SlowMoving Landslides, Vadose Zone Journal, 10, 496-511, 2011.

Van Bavel, M. and Nichols, C.: Theta and Profiler Soil Moisture Probes - Accurate Impedance Measurement Devices - New Applications, Technical Report, 2002.

Van Beek, L. P. H. and van Asch T. W. J.: A combined conceptual model for the effects of fissure-induced infiltration on slope stability, in: Process Modelling and Landform Evolution, Hergarten S, Neugebauer HJ (eds), Lecture Notes in Earth Sciences, 78, 147-167, 1999.

Van Schaik, L.: The role of macropore flow from PLOT to catchment scale, Ph.D. thesis, in: Netherlands Geographical Studies, University of Utrecht, Netherlands, 2010.

Zehe, E. and Fluhler, H.: Preferential transport of isoproturon at a plot scale and a field scale tile-drained site, J. Hydrol., 247, 100$115,2001$. 